\title{
Autoxidation of Tetralin in Water catalysed by Cobalt(II)-Pyridine Complexes bound to Polymer Colloids
}

\author{
Rama S. Chandran and Warren T. Ford* \\ Department of Chemistry, Oklahoma State University, Stillwater, Oklahoma 74078, U.S.A.
}

Cobalt(II)-pyridine complexes bound to $60 \mathrm{~nm}$ diameter latex copolymers of styrene, divinylbenzene, and either acrylic or methacrylic acid catalyse autoxidation of tetralin in water faster than cobalt(॥)-pyridine complexes in aqueous solution or cobalt(II) acetate in acetic acid.

Cobalt-pyridine (CoPy) complexes bound to copolymers of styrene and acrylic or methacrylic acid catalyse the autoxidation of 1,2,3,4-tetrahydronaphthalene (tetralin) dispersed in water [equation (1)]. Even though the solubility of tetralin in water, estimated to be less than $10^{-4} \mathrm{M}$ (naphthalene, $1 \times$ $10^{-4} \mathrm{M}$ at $25^{\circ} \mathrm{C}$; tetralin $1.4 \times 10^{-3} \mathrm{M}$ at $150^{\circ} \mathrm{C}$ ), ${ }^{1}$ oxidation of more than $60 \%$ of $0.06-0.13 \mathrm{M}$ dispersed tetralin in the aqueous colloids occurs in $24 \mathrm{~h}$ at $50^{\circ} \mathrm{C}$ at 1 atm pressure of dioxygen. The rate of tetralin oxidation with a colloidal CoPy catalyst is twice as fast as with aqueous CoPy and nine times as fast as with cobalt(II) acetate in acetic acid. The standard method of autoxidation of alkylaromatic hydrocarbons involves treatment with dioxygen in acetic acid with cobalt(II) as catalyst and $\mathrm{HBr}$ as promoter to yield 1,2,3,4-tetrahydro-1naphthol (1-tetrol) and 3,4-dihydronaphthalen-1(2H)-one (1tetralone) as the major products. ${ }^{2-4}$

Table 1. Colloidal copolymers and catalysts.

$\begin{array}{cccccc}\text { Catalyst } & \text { Copolymer } & \begin{array}{c}\mathrm{CO}_{2} \mathrm{H} / \\ \mathrm{Co}^{\mathrm{II}}\end{array} & \begin{array}{c}\mathrm{mg}-\mathrm{Co} / \\ \text { g polymer }\end{array} & \begin{array}{c}\text { Wt. } \% \\ \text { solids }\end{array} & \begin{array}{c}d / \\ \mathrm{nm}^{\mathrm{b}}\end{array} \\ \text { LC-1 } & 79: 20 \mathrm{MA}: 1 & 18.6 & 0.11 & 2.1 & 58 \\ \text { LC-2 } & 79: 20 \mathrm{MA}: 1 & 8.0 & 0.25 & 1.3 & 58 \\ \text { LC-3 } & 79: 20 \mathrm{AA}: 1 & 17.4 & 0.12 & 2.0 & 62 \\ \text { LC-4 } & 23: 76 \mathrm{AA}: 1 & 2.3 & 4.2 & 1.0 & 140\end{array}$

a $\mathrm{Mol} \%$ ratio of styrene : acrylic acid (AA) or methacrylic acid (MA): divinylbenzenes ( $55 \%$ technical grade) and ethylvinylbenzenes in the monomer mixture. ${ }^{b}$ Number average particle diameter measured on transmission electron micrographs.
Copolymer latexes of styrene, acrylic acid (AA), or methacrylic acid (MA), and divinylbenzene were prepared by emulsion polymerization using sodium dodecyl sulphate as the surfactant and $\mathrm{K}_{2} \mathrm{~S}_{2} \mathrm{O}_{8} / \mathrm{NaHSO}_{3}$ as a redox initiator. ${ }^{5}$ Crosslinking with divinylbenzene ensured that the polymer was insoluble during all subsequent experiments. The carboxylic acid groups were converted to $\mathrm{Co}^{\text {II }}$ salts via the potassium salt by addition of cobalt(II) acetate solution to the copolymer latex with agitation in an ultrasonic bath. The Coll latexes specified in Table 1 were purified by ultrafiltration through a $0.1 \mu \mathrm{m}$ cellulose acetate/nitrate membrane (Millipore) until the conductivity of the filtrate at $25^{\circ} \mathrm{C}$ was constant at $40 \mu \Omega^{-1}$ $\mathrm{cm}^{-1}$. An upper limit of $3 \times 10^{-6}$ for the fraction of $\mathrm{Co}^{\mathrm{II}}$ not bound to the latex was established by addition of 1,10 phenanthroline to the ultrafiltrate and u.v.-visible spectrophotometric analysis of the $\mathrm{Co}^{\text {II }}$ complex. By the same criterion, addition of $6 \mathrm{~mol}$ of pyridine per mol of $\mathrm{Co}^{\mathrm{Il}}$ to form the active catalysts did not extract cobalt ions from the latex. Autoxidations of tetralin are listed in Table 2 and illustrated in Figure 1.

A complete mechanism for the autoxidation of alkylaromatic hydrocarbons by cobalt(II) in acetic acid has not been established, ${ }^{6}$ although a complex rate law has been determined for tetralin. ${ }^{2,3} \mathrm{We}$ decline to speculate here on the mechanism with colloidal CoPy catalysts, and are continuing study of the kinetics to gain a better understanding of the processes and to prepare still more active catalysts.

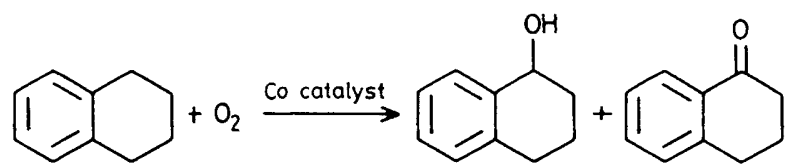

Table 2. Oxidation of tetralin using latex catalysts.a

Analysis, as mol $\%$ of initial tetralin

\begin{tabular}{ccccc} 
& & \multicolumn{3}{c}{ Initial composition } \\
\cline { 3 - 5 } Expt. & Catalyst $^{\mathrm{b}}$ & Co $^{\text {Il } / \mathrm{mm}}$ & Py/mM & Tetralin/mM \\
1 & LC-1 & 0.66 & 4.0 & 61 \\
2 & LC-1 & 0.66 & 4.0 & 61 \\
3 & LC-2 & 0.66 & 4.0 & 61 \\
4 & LC-3 & 1.40 & 8.4 & 130 \\
5 & LC-4 & 1.40 & 8.4 & 130 \\
6 & LC-1 & 1.90 & 12.0 & 100 \\
7 & CoPy & 1.90 & 12.0 & 100 \\
8 & CoAcg & 1.90 & - & 110
\end{tabular}

\begin{tabular}{|c|c|c|c|c|}
\hline \multirow{2}{*}{$\begin{array}{c}\mathrm{O}_{2} \\
\text { consumed }\end{array}$} & \multirow{2}{*}{$\begin{array}{l}\text { Tetralin } \\
\text { consumed }\end{array}$} & \multicolumn{3}{|c|}{ Products formed ${ }^{c}$} \\
\hline & & Tetrol & Tetralone & Otherd \\
\hline 69 & 65 & 22 & 43 & 3 \\
\hline 74 & 77 & 24 & 46 & 4 \\
\hline 62 & 58 & 21 & 37 & 2 \\
\hline 68 & 63 & 20 & 43 & 2 \\
\hline 48 & 45 & 16 & 27 & 1 \\
\hline 67 & 62 & 21 & 41 & 3 \\
\hline 45 & 43 & 15 & 28 & 2 \\
\hline 25 & 24 & 2.5 & 23 & 1 \\
\hline
\end{tabular}

a Reactions were carried out at $50 \pm 0.1^{\circ} \mathrm{C}$ for $24 \mathrm{~h}$ and an $\mathrm{O}_{2}$ pressure of $720 \mathrm{mmHg}$ ( $\mathrm{ca} .20 \mathrm{mmHg}$ less than atmospheric pressure) with magnetic stirring of $30.0 \mathrm{ml}$ of reaction mixture. Catalysts were equilibrated at $50^{\circ} \mathrm{C}$ under oxygen prior to addition of tetralin. $\mathrm{b}$ Table 1 . c From g.l.c. analysis of organic compounds extracted after coagulation of the latex catalyst with sodium chloride solution. d Unidentified product as weight \% of initial tetralin. For detailed analysis of tetralin autoxidation products see A. Robertson and W. A. Waters, J. Chem. Soc., 1948, 1574. c The mixture was agitated using a platform shaker having an amplitude of $2.5 \mathrm{~cm}$ and a frequency of $c a$. $1 \mathrm{~s}^{-1}$. ${ }^{f}$ Catalyst was soluble cobalt(II)-pyridine in water at $\mathrm{pH} 8$. g Cobalt(II) acetate in acetic acid. 


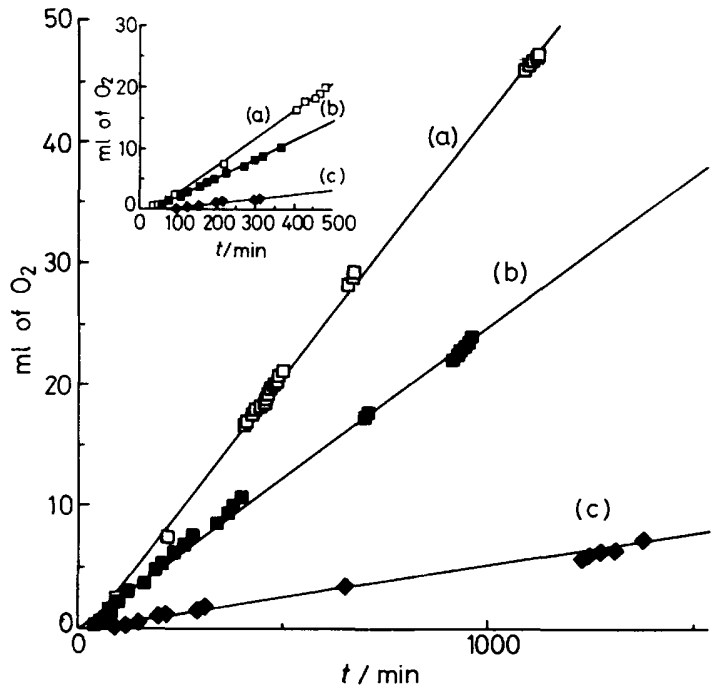

Figure 1. Oxygen consumption with time during autoxidation of tetralin catalysed by (a) LC-1, (b) aqueous $\mathrm{CoPy}$, and (c) cobalt(II) in acetic acid. Inset shows induction periods.
We thank the U.S. Environmental Protection Agency for support of grant R812298-01-0.

Received, 26th August 1987; Com. 1257

\section{References}

1 H. Stephen and T. Stephen, eds., 'Solubilities of Inorganic and Organic Compounds,' Pergamon Press, New York, 1963; pp. 533, 616.

2 J. K. Kochi and R. A. Sheldon, 'Metal-Catalyzed Oxidations of Organic Compounds,' Academic Press, New York, 1981, ch. 3, pp. $38-42$; ch. 5, pp. $120-127$.

3 Y. Kamiya, A. Beaton, A. Lafortune, and K. U. Ingold, Can. J. Chem., 1963, 41, 2020; A. E. Woodward and R. B. Mesrobian, J. Am. Chem. Soc., 1953, 75, 6189; Y. Kamiya, J. Catal., 1974, 33, 480; A. S. Hay and H. S. Blanchard, Can. J. Chem., 1965, 43, 1306.

4 Y. Kamiya and M. Kashima, J. Catal., 1972, 25, 326.

5 G. A. Campbell and D. A. Upson, Macromol. Synth., in the press; D. C. Blackley and S. A. R. D. Sebastian, Brit. Polym. J., 1987, 19, 25.

6 S. Lunak, M. Vaskova, P. Lederer, and J. Vepreksiska, J. Mol. Catal., 1986, 34, 321; E. Baciocchi, L. Mandolini, and C. Rol, J. Org. Chem., 1980, 45, 3906. 